\title{
Identification and analysis of UK and US BIM standards to aid collaboration
}

\author{
G. Lea ${ }^{1}$, A. Ganah ${ }^{1}$, J. Goulding ${ }^{1} \&$ N. Ainsworth ${ }^{2}$ \\ ${ }^{1}$ The Grenfell-Baines School of Architecture, Construction \\ and Environment, University of Central Lancashire (UCLan), UK \\ ${ }^{2}$ Frank Whittle Partnership (FWP), UK
}

\begin{abstract}
The UK government's ambitious plans to meet Building Information Modelling (BIM) Maturity Level 2 by 2016 places significant pressure on construction companies to ensure their existing BIM capability meets the mandated requirements. This poses a significant challenge to organisations, as BIM requires a radical repositioning in the way buildings are designed and managed, with collaboration playing a pivotal role in this process. For example, many construction companies still use traditional 2D CAD files, bespoke data, and drawing standards that are company-specific (and often non-compliant). These types of 'bad habits' and parochial standards are difficult to share or replicate. Conversely however, there is a real opportunity for companies to proactively embrace this transition to BIM through a number of conduits, not least: the installation of industry standard best practices; embedding improved collaborative approaches; improving data veracity, flow and coordination throughout the design, construction and operational phases. This research aims to identify and analyse UK and US BIM standards, along with their inter-relationships to promote best practice. Research data was collated through a comprehensive literature review of UK and US standards and collaboration publications ensuing 2007. Initial findings suggest that UK standards have been strategically developed in conjunction with one another, whereas US standards appear non-cognate and developed in isolation. Further research is required to critically compare and contrast the content of UK and US standards, along with initiatives published by other countries to develop a holistic UK BIM standards roadmap.

Keywords: BIM, adoption, ICT, collaboration, construction, design, standards.
\end{abstract}




\section{Introduction}

Given the unique nature of construction projects, paper-based drawings and fragmented working relationships with different stakeholders; the Architectural, Engineering and Construction (AEC) industry suffers with problems often not encountered by other industries. The governments push to tackle these issues led to a technical and process revolution termed 'BIM' which is being embraced by the AEC industry [1]. National Institute of Building Sciences (NIBS) [2] describes BIM as "a digital representation of physical and functional characteristics of a facility. A BIM is a shared knowledge resource for information about a facility forming a reliable basis for decisions during its life-cycle; defined as existing from earliest conception to demolition".

The transition to computer-aided design (CAD) did not radically alter the way professionals worked, it simply fast tracked the delivery. The emphasis with CAD was on format and output, whereas BIM focuses on open information and workflows [3]. BIM adoption is rapidly becoming a matter of importance for the UK construction industry that has faced barriers and challenges to increase productivity, efficiency and quality.

The UK Government Construction Clients Board appointed the BIS/industry working group to develop the 2011 'Building Information Modelling (BIM) Working Party Strategy Paper' [4] which outlines how government clients can make progressive use of BIM on public sector schemes. The report presents a framework which incorporates seven key education and support areas (contract and legal, delivery standards, training and support systems, Construction Operations Building Information Exchange (COBie) definitions, data management server, cost-benefit analysis, and communications). However, Kassem et al. [5] review of existing studies and initiatives revealed that BIM protocols are mainly proposed at industry-wide level, thus require substantial modification before being applied at project level. The majority of AEC firms would benefit from a clear set of guidelines and standards which present a measurable and repeatable methodology to implement BIM at organisational level [6].

\section{Research methodology}

Research data will be collated through a comprehensive literature review of UK and US standards and collaboration publications. Given the recent advancements in BIM technology and standardisation measures, literature will be confined to industry standards, guidelines and initiatives ensuing 2007. Publications will be presented in in tabular and illustration format for initial comparison.

\section{Technical}

Substantial effort has been made to help define standardised BIM methodologies and tools for documenting the information requirements of design, construction 
and operational processes. However, Ganah and John [7] argue that task groups formed by various UK institutions such as the RICS, CIB, CIOB, RIBA, etc., are not yet fully integrated to provide a holistic, long-term approach to collaborative processes. Findings suggest that systematic approaches to BIM implementation weren't adopted by the UK AEC industry prior to the development of Publically Available Specification (PAS) 1192-2:2013 [8], and the BIM overlay to the RIBA Outline Plan of Work 2012 [9]. Becerik-Gerber et al. [10] identified that $71 \%$ of the BIM companies questioned, utilise BIM standards, of which only $35 \%$ adopted industry standards, the remaining $65 \%$ developed their own company standards.

The US have developed major initiatives including the US National Building Information Modeling Standard (NBIMS) and IAI buildingSMART [2], but the question remains; could the UK develop standards from lessons learnt in the US, or do existing standards published by UK institutions facilitate collaborative BIM?

\subsection{Process}

\subsubsection{Employer's information requirements}

The British Standards Institution (BSI) [11] define the Employer's Information Requirements (EIR) as a "pre-tender document setting out the information to be delivered, and the standards and processes to be adopted by the supplier as part of the project delivery process". Successful procurement is reliant on a good EIR, which should contain information exchange and collaborative working requirements, and then incorporated into a suppliers Project Execution Plan (PEP). The EIR must only contain enough information to answer the 'plain language questions' required at that particular stage, at an appropriate level of detail [8]. The BIM Task Group [12] EIR guidance document includes standard responses which, in many cases, can be adopted without amendment. Although, certain aspects require editing based on project specific requirements. An alternative EIR guidance document has been produced by the Consortium of Local Authorities in Wales [13] which also provides an example format; guides the user through the EIR process; and refers heavily to PAS 1192-2 [8], PAS 1192-3 [14], and British Standard (BS) 1192:2007 [15].

\subsubsection{BIM Execution Plan}

The BSI [8] describe the 'Pre-Contract Building Information Modelling (BIM) Execution Plan (BEP)' [16] as facilitating the procurement process, and the 'Post Contract-Award Building Information Modelling (BIM) Execution Plan (BEP)' [17] as assisting in the management of delivery on the project, including the contractual information exchange requirements set out in the BIM Protocol and wider project deliverables established by the contract. The requirements and differences between the production of the Pre-Contract BEP and Post Contract BEP are highlighted in Table 1.

The Construction Project Information Committee (CPIc) [16, 17] are the only BEP standards within the UK and US which incorporate 'pre' and 'post' contract project planning, whilst providing a 'user friendly' BEP template. Other guides and templates are readily available from both countries which facilitate the BEP 
process (see Table 2). However, templates such as AEC [18], Georgia State Financing and Investment Commission [19], Princeton University [20], and US Air Force [21] are clear and logically structured, but lack the detail of CPIc $[16,17]$.

Table 1: $\quad$ Pre-contract and post-contract BEP requirements.

\begin{tabular}{|c|c|c|c|}
\hline Category & Requirements & 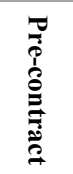 & 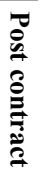 \\
\hline & Everything requested in the employer's information requirements & • & • \\
\hline \multirow[t]{8}{*}{ Management } & Project goals for collaboration and information modelling & $\bullet$ & \\
\hline & Major project milestones consistent with the project programme & • & • \\
\hline & $\begin{array}{l}\text { Project Information Model (PIM) deliverable strategy } \\
\text { (e.g. the CIC Schedule) }\end{array}$ & $\bullet$ & • \\
\hline & Roles, responsibilities and authorities & & • \\
\hline & $\begin{array}{l}\text { Survey strategy including the use of point clouds, light detecting } \\
\text { and ranging or global navigation satellite systems }\end{array}$ & & • \\
\hline & Existing legacy data use & & • \\
\hline & Approval of information & & • \\
\hline & PIM authorisation process & & • \\
\hline \multirow[t]{5}{*}{$\begin{array}{l}\text { Planning and } \\
\text { documentation }\end{array}$} & Revised PIP confirming the capability of the supply chain & & \\
\hline & $\begin{array}{l}\text { Agreed project processes for collaboration and information } \\
\text { modelling }\end{array}$ & & • \\
\hline & Agreed matrix of responsibilities across the supply chain & & • \\
\hline & Task Information Delivery Plan (TIDP) & & • \\
\hline & Master Information Delivery Plan (MIDP) & & • \\
\hline \multicolumn{3}{|c|}{ Standard methodThe volume strategy } & - \\
\hline & $\begin{array}{l}\text { PIM origin and orientation (which may also be geo-references to the } \\
\text { earth's surface using specified projection) }\end{array}$ & & • \\
\hline & File naming convention & & • \\
\hline & Layer naming convention, where used & & • \\
\hline & Agreed construction tolerances for all disciplines & & • \\
\hline & Drawing sheet templates & & • \\
\hline & Annotation, dimensions, abbreviations and symbols & & • \\
\hline & Attribute data & & • \\
\hline \multirow[t]{3}{*}{ The IT solutions } & Software versions & & • \\
\hline & Exchange formats & & • \\
\hline & Process and data management systems & & - \\
\hline
\end{tabular}


Table 2: $\quad$ BEP standards, guidelines, and templates.

\begin{tabular}{llll}
\hline \hline Code & Document title & Issuer, Year & $\begin{array}{l}\text { Doc. } \\
\text { type }\end{array}$ \\
\hline \hline UK01 & AEC (UK) BIM Protocol: Project BIM Execution Plan & AEC, 2012 & G \\
UK02 & CPIx Pre-Contract BIM Execution Plan (BEP) & CPIc, 2013 & S, T \\
UK03 & CPIx Post Contract-Award BIM Execution Plan (BEP) & CPIc, 2013 & S, T \\
\hline US01 & BIM Project Execution Planning Guide & CICRG, 2010 & G \\
US02 & GSFIC BIM Execution Plan - Series 1: Template & GSFIC, 2012 & T \\
US03 & Princeton University BIM Execution Plan Template & PU, 2012 & T \\
US04 & US Air Force BIM Project Execution Plan (USAF PxP) & USAF, 2010 & T \\
US05 & BIM Project Execution and Standards Guide & WMU, 2011 & G \\
US06 & Building Information Modeling (BIM) Guidelines & USC 2012 & T \\
US07 & State of Ohio Building Information Modeling Protocol & ODAS, 2010 & T \\
\hline \hline${ }^{1}$ S - Standard, G - Guide, T - Template. & & \\
\hline
\end{tabular}

\subsubsection{Design standards UK}

The development of BIM standards in the UK is gaining increased support from industry bodies, regulators, and construction professionals through shared knowledge and understanding. One industry body at the forefront of BIM standardisation is the BSI (see Table 3). Although the development was facilitated by the BSI, PAS is not to be regarded as a British Standard [22]. Its publication enables a specification to be rapidly developed to fulfil an immediate industry need. PAS may be considered for further development as a British Standard, or constitute part of the UK input into the development of a European or International Standard $[8,14]$.

Previous versions of BS 1192 which date back to 1998 only provided guidance for the structuring and exchange of CAD data. The 2007 version places more emphasis on collaborative processes and has been upgraded to a Code of Practice, thus design teams will need a very good reason not to implement it. This standard also offers definitive guidance on technicalities such as how to use well-structured names for the directories, files and layers [23]. BSI recently published BS 11924:2014 [11] which aligns closely with BS 1192:2007 [15], PAS 1192-2:2013 [8] and PAS 1192-3:2014 [14], all of which document best practice for the management of collaborative projects using Facilities and Asset Information Modelling based design, construction and use. BS 1192-4:2014 [11] on the other hand deals specifically with the UK usage of COBie facility information exchange schema between the employer and the supply chain [11].

Alternative BIM guidelines have been developed by The AEC (UK) Initiative. Turco [24] describes the AEC [25] 'AEC (UK) BIM Protocol for Autodesk Revit' 
as a workable implementation of the AEC [26] 'AEC (UK) BIM Protocol'. Both standards are closely aligned with BS 1192:2007 [15], however, these standards have no legislative backing but are still written in the context of rules to be followed rather than points to cover. AEC's publications are intended to support all BIM work undertaken within a practice to enable a unified, practical, and coordinated approach to BIM in a design environment.

Standards in the UK are relatively straightforward, logical and clearly identify how each document relates to other standards (see Table 3). The only difficulty lies in deciding which standard to adopt and whether standards developed outside the UK offer a more comprehensive solution.

\subsubsection{Design standards US}

The US has published many long standing BIM publications thanks to the work of industry bodies, government departments, academic institutions, and local authorities. NBIMS claim to be a key element in the building industry transformation and establish standard definitions for building information exchanges to support critical business scenarios using standard semantics and ontologies. NBIMS is made up of a committee from NIBS, and the Facility Information Council. The vision for NBIMS is "an improved planning, design, construction, operation, and maintenance process using a standardised machinereadable information model for each facility, new or old, which contains all appropriate information created or gathered about that facility in a format useable by all throughout its lifecycle" [2, p. 6]. NBIMS are likely to be the catalyst in changing the current AEC industry processes by introducing much needed order and standardisation to the definition and use of building data, along with the development of the first Capability Maturity Model [27].

The American Institute of Architects (AIA) issued 'Integrated Project Delivery: A Guide' [28] which focuses more on the principles of Integrated Project Delivery but doesn't refer to BIM. The AIA published its first contract in 2008 which specifically refers to BIM [29]. The AIA [30] defined Levels of Detail (LOD) through a sliding scale of LOD 100-500 (LOD 100: Conceptual, LOD 200: Approximate geometry, LOD 300: Precise geometry, LOD 400: Fabrication, and LOD 500: As-built) [31]. Statsbygg [32] claim the AIA [30] LOD concept, established through the E202 Protocol is now starting to be adopted throughout the world. The AIA developed further standards to meet the rapid uptake of BIM, these include AIA [33], which establishes protocols for the development, use, transmission, and exchange of digital BIM data; and AIA [34], which is a digital data protocol form to be used in conjunction with AIA [33].

Analysing US BIM standards in highlights the fragmented nature, with the majority having been developed in isolation. NIBS [2] presentation makes difficult reading and is far too lengthy at 183 pages. However, alternative standards such as University of Southern California [35], Ohio Department of Administrative Services [36], and Indiana University [37] are well presented but lack the detail of NIBS [2] or equivalent UK standards. 


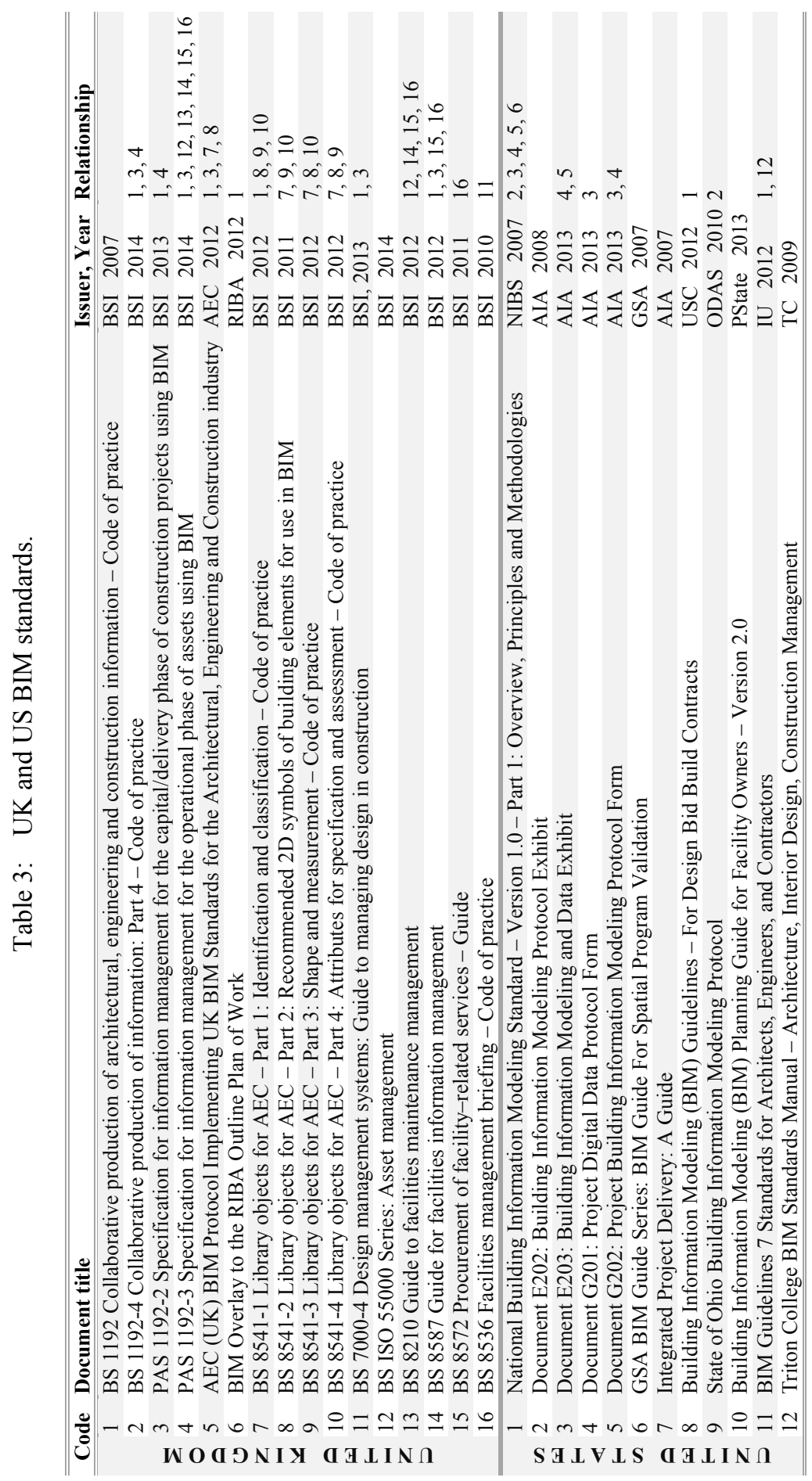




\subsection{Information standards}

\subsubsection{Information classification}

A large percentage of project documentation is produced in text format, thus methods for organising and improving the management of building data is essential in a collaborative BIM process.

UniFormat is a standard for classifying building elements and related sitework, ensuring consistent economic evaluation of construction projects and enhanced project management during concept design and operational project stages, whilst MasterFormat provides a master list of numbers and titles classified by work results or construction practices, used to organise project manuals, detailed cost information, and relate drawing notations to specifications. OmniClass is a newly developed AEC industry-wide initiative led by the Construction Specifications Institute and endorsed by The Information Architecture Institute which is intended to be the most comprehensive classification format, which encapsulates all project phases (see Figure 1).

\subsubsection{Information exchange}

BIM presents many interoperability issues given the reliance on embedded information. The first step towards resolving these issues and developing a computerised process for information interoperability within the AEC industry was the Industry Foundation Classes (IFC), 1999. IFC's are defined by the buildingSMART alliance and represent the accepted industry standard for design models and information exchange. IFC's include object specifications, classifications and provide a useful structure for data transfer between applications. However, IFC's still require further development, especially relating to the exporting of non-geographical data, complex geometries, parametrically modelled components, complexity of language, and large file sizes [38]. International Framework for Dictionaries (IFD) is an open terminology standard, where concepts and terms are given a unique identification number and tagged with a Globally Unique ID. Information Delivery Manual (IDM) is then used to specify exactly what information is exchanged, whilst retaining links to the IFC model. Benefits of IDM can be leveraged during all project phases (see Figure 1).

NBIMS initiated project COBie in December 2006 to support the handover of projects between builders and operators. The primary objectives of COBie was to identify the data and information exchange needs of facilities managers, operators, and asset managers upstream of the facility life cycle [39] (see Figure 1); and provide a robust framework for information organisation. The COBie standard is a key requirement stipulated in the BIM Task Group [4] report [40]. All public sector projects in the UK will require COBie data at designated data drops in the project lifecycle, thus it will be a key industry requirement to generate, validate, and share COBie data in a collaborative BIM process. Standards and guidance documentation to facilitate this process include BS 1192-4 [11], BIM Task Group [41], and PAS 1192 [8, 14] 'Information Delivery Cycle' diagram. 


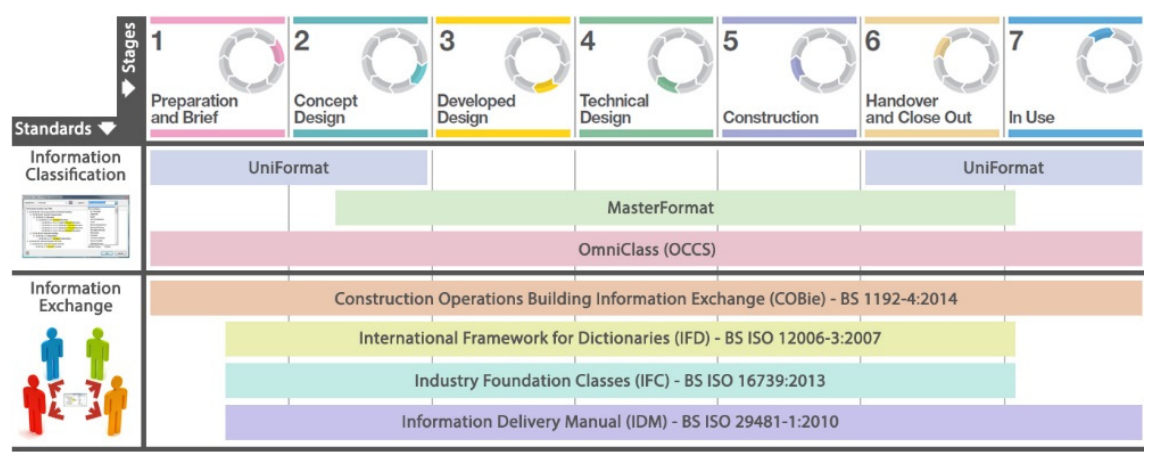

Figure 1: Conceptual information standards framework by RIBA Project Phase.

\section{Conclusion}

Findings clearly indicate that the construction industry is still trying to find its feet with standardising processes and documentation to reap the inherent benefits of BIM. Although, the adoption of industry standards and the introduction of project planning measures was identified as critical for the successful delivery of BIM, few companies have adopted them to date. The key to successful BIM collaboration is to closely follow industry standards, along with the production of a good EIR, BEP, and PEP specific to the project and company's requirements.

There appears to be several UK BIM standards and initiatives such as PAS 1192-2:2013 [8], PAS 1192-3:2014 [14], BS 1192:2007 [15], and BS 1192-4:2014 [11] which seem to be clear, logical and heavily promoted by industry bodies. Alternative guidance documents developed by the AEC [25, 26]; although lacking legislative powers, are closely aligned to BS 1192:2007 [15] and enable a practical, and coordinated approach to BIM in a design environment. Aside from BS 1192:2007 [15], the other documents have only recently been published, thus have not been the subject of research to determine which standards the industry is using, and whether there are alternative publications which offer a more holistic delivery of BIM. The most commonly used US standards include NIBS [2], AIA $[30,33,34]$. However, this paper highlights the fragmentation between US standards and guidance documentation. On initial inspection, US publications appear poorly presented, too complex and/or lack detail.

In a collaborative BIM process, there is an exigent need to adopt a standard classification model such as UniFormat, MasterFormat, or OmniClass. However, whilst OmniClass provides one solution. COBie data and information exchange standards are commonly overlooked by industry, but this is a key requirement stipulated in the UK governments BIM Task Groups [4] report. IFC proves to be a useful tool in data and model exchange, however more research and development needs to be undertaken to tackle large file sizes, non-geographical data, complex geometries, and parametrically modelled components. IFC standards should be used in conjunction with IFD and IDM frameworks to enable the complete information exchange solution. 
Further research is required to critically compare and contrast the content of the UK and US standards identified within this paper, but also analyse standards and initiatives developed by other countries (Australia, Netherlands, etc.) for a more comprehensive outcome. This would help to identify the best placed publications to develop a measurable and repeatable approach through a bespoke UK BIM standards roadmap.

\section{References}

[1] A. Rahman and S. Suwal, "Diverse Approach of BIM in AEC Industry: A Study on Current Knowledge and Practice," in 30th CIB W78 International Conference, Beijing, 2013.

[2] NIBS, "United States National Building Information Modeling Standard: Version 1 - Part 1: Overview, Principles and Methodologies," National Institute of Building Sciences, 2007.

[3] H. Livingston, "National standards evolve slowly: while the national CAD standard plugs along and plugs in, the national BIM standards project gains momentum," Cadalyst, 16 August 2007.

[4] BIM Task Group, "A Report for the Government Construction Client Group - Building Information Modelling (BIM) Working Party Strategy Paper," March 2011.

[5] M. Kassem, N. Iqbal, G. Kelly, S. Lockley and N. Dawood, "Building Information Modelling: Protocols for Collaborative Design Processes," Journal of Information Technology in Construction (ITcon), vol. 19, pp. 126-149, July 2014.

[6] B. Succar, "Building Information Modelling Maturity Matrix," Handbook of Research on Building Information Modeling and Construction Informatics: Concepts and Technologies, pp. 1-50, 2009.

[7] A. Ganah and G. John, "Achieving Level 2 BIM by 2016 in the UK," in 2014 International Conference on Computing in Civil and Building Engineering (ICCCBE 2014), Orlando, 2014.

[8] BSI, "PAS 1192-2 Specification for information management for the capital/delivery phase of construction projects using building information modelling," British Standards Institution, 2013.

[9] RIBA, "BIM Overlay to the RIBA Outline Plan of Work," Royal Institution of British Architects, 2012.

[10] B. Becerik-Gerber, F. Jazizadeh, N. Li and G. Calis, "Application Areas and Data Requirements for BIM-Enabled Facilities Management," Journal of Construction Engineering and Management, 15 June 2011.

[11] BSI, "BS 1192-4 Collaborative production of information, Part 4: Fulfilling employer's information exchange requirements using COBie - Code of practice," British Standards Institution, 2014.

[12] BIM Task Group, "Employer's Information Requirements: Core Content and Guidance Notes," 2013.

[13] CLAW, "Employers Information Requirements: The CLAW All Wales BIM Toolkit," Consortium of Local Authorities in Wales, 2013. 
[14] BSI, "PAS 1192-3 Specification for information management for the operational phase of assets using building information modelling," British Standards Institution, 2014.

[15] BSI, "BS 1192:2007 Collaborative production of architectural, engineering and construction information - Code of practice," British Standards Institution, 2007.

[16] CPIc, "CPIx Pre-Contract Building Information Modelling (BIM) Execution Plan (BEP)," Construction Project Information Committe, 2013.

[17] CPIc, "CPIx Post Contract-Award Building Information Modelling (BIM) Execution Plan (BEP)," Construction Project Information Committe, 2013.

[18] AEC, “AEC (UK) BIM Protocol Project BIM Execution Plan," 2012.

[19] GSFIC, "GSFIC BIM Execution Plan - Series 01: Template," Georgia State Finincing and Investment Commission, 2012.

[20] Princeton University, "Princeton University BIM Execution Plan Template," 2012.

[21] USAF, "US Air Force BIM Project Execution Plan (USAF PxP)," US Air Force, 2010.

[22] N. Dawood and N. Iqbal, "Building Information Modelling: Scope for Innovation in the AEC Industry," in 10th International Conference on Construction Applications of Virtual Reality, 2010.

[23] A. Glema, "Public Buildings Service BIM Standards as Mandatory Procedures for Architects and Engineers," in Computer Methods in Mechanics, Poznan, 2013.

[24] M. Turco, "Standard protocols in BIM methodologies," in 14th International Conference on Computing in Civil and Building Engineering, Moscow, Russia, 2012.

[25] AEC, "AEC (UK) BIM Protocol for Autodesk Revit: Additional detail and enhancements for implementation of the AEC (UK) BIM Protocol for Autodesk Revit users - Version 2.0," 2012.

[26] AEC, "AEC (UK) BIM Protocol: Implementing UK BIM Standards for the Architectural, Engineering and Construction Industry - Version 2.0," 2012.

[27] V. Bazjanac, "Impact on the U.S. National Building Information Model Standard (NBIMS) on Building Energy Performance Simulation," Lawrence Berkeley National Laboratory, University of California, Berkeley, USA, 2008.

[28] AIA, "Integrated Project Delivery: A Guide - Version 1," 2007.

[29] F. Sabongi, "The Integration of BIM in the Undergraduate Curriculum: an analysis of undergraduate courses," Minnesota State University, Mankato, Minnesota, 2009.

[30] AIA, "Document E202: Building Information Modeling Protocol Exhibit," The American Institute of Architects, Washington, DC, 2008.

[31] M. Hooper and A. Ekholm, "A BIM-Info Delivery Protocol," Australian Journal of Construction Economics and Building, 2012.

[32] Statsbygg, "BIM-Manual 1.2: Statsbygg Building Information Manual Version 1.2 (Draft)," Statsbygg, Oslo, 2011. 
[33] AIA, "Document E203: Building Information Modeling and Digital Data Exhibit," The American Institute of Architects, 2013.

[34] AIA, "Document G201: Project Digital Data Protocol Form," 2013.

[35] USC, "Building Information Modeling (BIM) Guidelines - For Design Bid Build Contracts," University of Southern California, 2012.

[36] Ohio DAS, "State of Ohio Building Information Modeling Protocol," Ohio Department of Administrative Services, 2010.

[37] IU, "BIM Guidelines \& Standards for Architects, Engineers, and Contractors," Indiana University, 2012.

[38] L. Sabol, "Challenges in Cost Estimating with Building Information Modeling," Design + Construction Strategies, pp. 1-16, 2008.

[39] E. East and W. Brodt, "BIM for Construction Handover," Journal of Building Information Modeling, pp. 28-35, 2007.

[40] E. Sackey, M. Tuule and A. Dainty, "BIM Implementation: From Capability Maturity Models to Implementation Strategy," in Sustainable Building Conference 2013, Coventry SB13, 2013.

[41] BIM Task Group, "COBie Data Drops - Structure, uses \& examples," 2012. 